\title{
El Factor de Crecimiento Epidérmico y la Diferenciación Celular del Epitelio Mamario
}

\author{
Epidermal Growth Factor and Mammary Epithelial Differentiation
}

Ricardo Cornejo Uribe

CORNEJO, U. R. El factor de crecimiento epidérmico y la diferenciación celular del epitelio mamario. Int. J. Morphol., 29(3):821$824,2011$.

RESUMEN: El objetivo de este artículo es presentar una revisión relativa a evidenciar las características generales, estructura y funcionalidad de los factores de crecimiento con especial énfasis en precisar el rol que ejerce el factor de crecimiento epidérmico (EGF) como agente generador del proceso de diferenciación celular en el epitelio mamario.

PALABRAS CLAVE: Factor de Crecimiento Epidérmico; Diferenciación celular; Epitelio mamario.

\section{INTRODUCCIÓN}

Los factores de crecimiento corresponden a un conjunto de moléculas de naturaleza proteica y/o péptidos biorreguladores cuya funcionalidad fundamental radica en el control del ciclo celular regulando el desarrollo de las distintas etapas de éste, llevando finalmente a las células a enfrentar el mecanismo mitótico y de este modo generar la proliferación celular. Sin embargo, estas moléculas orgánicas participan también estimulando tanto la diferenciación como la migración celular.

Actualmente se han identificado y caracterizado un gran número de factores de crecimiento, básicamente a partir de experimentación con células eucarióticas mantenidas en cultivo, entre los que podemos destacar (Gospodarowicz \& Moran, 1976; Jiménez de Asua, 1980):

El derivado de plaquetas: PDGF (platelet-derived growth factor).

El transformante beta. TGF-beta.

De fibroblastos: FGF.

De crecimiento epidérmico: EGF.

De hepatocitos: HGF.

De crecimiento endotelial vascular: VEGF.

De crecimiento insulínico tipo I: IGF-1.

Estimulante de colonias de granulocitos: G-CSF.
Todos estos factores de crecimiento comparten características específicas para realizar sus funciones estimulantes destacando aquella relativa a fusión con moléculas receptoras ubicadas en la membrana plasmática de las células blanco generando señales las cuales son transmitidas posteriormente hacia el interior del citoplasma mediante la activación de enzimas con actividad kinásica que fosforilan ciertos sustratos proteicos constituyendo de este modo, una cascada de señales conocida como transducción que finaliza activando la expresión génica y produciendo la transcripción específica de ciertos genes los que serán traducidos en los ribosomas constituyéndose en la respuesta celular a un determinado factor de crecimiento (Carpenter \& Cohen, 1979).

\section{DESARROLLO Y DISCUSIÓN}

Con respecto específicamente al factor de crecimiento epidérmico (EGF) fue descubierto en 1962 por Stanley Cohen en la Universidad de Vanderbilt obteniendo por ello el premio Nobel en medicina y fisiología en 1986 (Hall, 2009). La patente para el uso del EGF como cosmético fue otorgada en 1989 a Greg Brown (Brown, 1997).

Departamento de Ciencias Básicas. Facultad de Medicina. Universidad de La Frontera, Temuco, Chile. 
El EGF humano corresponde a una molécula proteica que contiene 53 residuos de aminoácidos con un peso molecular de $6025 \mathrm{Da}$, además posee 3 enlaces disulfuros en su configuración intramolecular (Carpenter \& Cohen, 1990) y es codificado por un gen localizado en el cromosoma 4 (Massagué \& Pandiella, 1993; Boonstra et al., 1995).

Este factor juega un importante rol en la regulación del crecimiento celular, proliferación, diferenciación y sobrevivencia (Herbst, 2004) funciones precisadas desde su obtención desde glándulas submandibulares y parótidas de rata descubriéndose además que el EGF salival es un agente regulador del yodo como así mismo actúa manteniendo la integridad del tejido gástrico, entre otras funciones (Venturi \& Venturi, 2009).

EGF ha sido también encontrado en plaquetas humanas, macrófagos, orina, leche y plasma (Cotran et al., 2005).

Se ha comprobado que tanto el EGF como TGF-alfa poseen el mismo receptor conocido como EGFR, el cual en la especie humana es codificado por el gen c-erbB1 ubicado en el brazo corto del cromosoma 7 (Tsui \& Farral, 1991) y que consiste en una familia de glicoproteínas integrales de la membrana plasmática que poseen 1186 aminoácidos con peso molecular de $170 \mathrm{KDa}$ constituido por un dominio extracelular amino terminal, un dominio transmembrana y un dominio citoplasmático carboxilo terminal donde se ubica el sitio catalítico responsable de la actividad tirosina kinasa intrínsica (Hernandez-Sotomayor \& Carpenter, 1992) denominado como HER1, Erb B1 o simplemente EGRF (Kumar et al., 2005).

Se ha evidenciado también que EGF posee alta afinidad con su receptor en la superficie celular estimulando instantáneamente una actividad tirosina-kinasa que inicia una señal de transducción generando una amplificación de esta señal a modo de cascada que resulta en una multitud de modificaciones citosólicas tales como un notable incremento en los niveles de calcio, aumento en el mecanismo glicolítico y de síntesis proteica y aumento en la expresión de ciertos genes incluyendo el gen para la síntesis tanto del propio EGFR, como igualmente para la síntesis de DNA y por ende a la proliferación celular, diferenciación y supervivencia celular, prevención o inducción de apoptosis y motilidad celular (Fallon et al., 1984).

Tonelli \& Sorof (1980) demostraron que el EGF poseía potencialidad para promover tanto el desarrollo de la glándula mamaria mantenida en cultivo como de igual manera estimular el crecimiento de las células de cáncer mamario in vitro.
Efectivamente, puesto que hemos estudiado a través de un estudio morfométrico cuantificando las variaciones morfológicas generadas por cambios en la cantidad y características de organelos producto de la diferenciación celular (Cornejo et al., 1995) precisando el rol del EGF en la línea de epitelio mamario HC11 derivada de COMMA-1D obtenida de glándula mamaria de rata BALB/ c en mitad de la preñez. Cuando estas células son mantenidas en cultivo mantienen un contacto muy estrecho disponiéndose a modo de un epitelio cúbico en monocapa. Además, ellas retienen características de la diferenciación normal de la glándula como la síntesis y secreción de b caseína, la principal proteína de la leche (Ball et al., 1988).

Estas células son inducidas a diferenciar por la acción de estímulos hormonales de prolactina, insulina y dexametasona. Prolactina induce la transcripción de genes correspondientes a la proteína de la leche en células epiteliales mamarias y además responsable no sólo por un aumento en la tasa de transcripción de RNA mensajero para b caseína sino también acumulándolo en el citoplasma y por tanto aumentando su vida media (Guyette et al., 1979).

Insulina con su funcionalidad anabólica estimulando igualmente la síntesis proteica de estas células, mientras que dexametasona, glicocorticoide induciendo poderosamente la diferenciación terminal de las células mamarias, actuando sinergicamente con prolactina induciendo la expresión de los genes para b caseína (Doppler et al., 1989).

Estas células del epitelio mamario reciben también las estimulaciones del EGF, agente mitogénico para células epiteliales mantenidas en cultivo el cual se combina con su receptor especifico con actividad tirosina kinasa a nivel de la membrana plasmática fosforilando proteínas citoplasmáticas, etapa fundamental en el desencadenamiento de la respuesta mitogénica (Carpenter \& Cohen, 1990).

En este sentido, Taberna et al. (1991), además de describir los receptores tirosina kinasa para el EGF muestran igualmente que, la activación de ellos constituye una etapa fundamental en la adquisición de competencia en la respuesta a las estimulaciones de las hormonas lactogénicas. La adición del EGF al medio de cultivo por lo menos durante dos días es esencial para la producción de b caseína, sin embargo, fue demostrado que cultivos de HC11, ya aptos para diferenciar, son capaces de sintetizar grandes cantidades de b caseína en presencia hormonal por hasta tres días después de retirado el EGF, demostrándose que la funcionalidad y/o efecto del EGF es de larga duración (Hynes et al., 1992).

Fue también observado que la activación del EGFR 
simultáneamente con la inducción de las hormonas lactogénicas tiene un efecto negativo sobre la síntesis de b caseína (Hynes et al., 1992).

En resumen, se observan tres efectos fenotípicos resultantes de la activación del EGFR en células HC11:

1.- EGF es un potente agente mitogénico

2.- Proporciona un estadio de pre-diferenciación en HC11, o sea confiere competencia para la respuesta a las hormonas lactogénicas

3.- La activación del EGFR inhibe la respuesta a las hormonas lactogénicas cuando EGF está presente en el medio de cultivo, la inducción solo acontece después del retiro del factor.

Por lo tanto, se demuestra que las vías intracelulares de transducción de señales que derivan de diferentes hormonas y que utilizan diferentes mecanismos intracelulares pueden reaccionar sinergicamente e influenciar la transcripción génica tanto positiva como negativamente (Groner et al., 1992).
Como resultado de los mecanismos señalados, una célula altamente indiferenciada perteneciente al epitelio mamario descrita como HC11 GM, caracterizada básicamente por presentar un gran núcleo mayoritariamente con eucromatina y un citoplasma con escasos organelos tales como: mitocondrias, cisternas de retículo endoplasmático rugoso y lisosomas y gran cantidad de ribosomas libres, se diferencia entonces producto de las estimulaciones tanto hormonales lactogénicas como del EGF a una célula que posee capacidad de sintetizar ß caseína, denominada HC11 IM aumentando su volumen citoplasmático y disminuyendo progresivamente el volumen nuclear. A nivel citoplasmático gran cantidad de mitocondrias de variadas formas, cisternas de retículo rugoso y complejo de Golgi, gotas de lípidos, lisosomas y ribosomas libres son estructuras que caracterizan a este tipo celular.

De igual modo, una característica exclusiva de estas células diferenciadas es la presencia citoplasmática de agrupaciones de filamentos intermediarios de citoqueratina distribuidos al azar y que es utilizado como marcador de diferenciación celular en este epitelio mamario (Cornejo et al.).

CORNEJO, U. R. Epidermal growth factor and mammary epithelial differentiation. Int. J. Morphol., 29(3):821-824, 2011.

SUMMARY: The objective of this article is to present a review referred to general characteristics, such as structure and functionality of the growth factors, particularly those related to the Epidermal Growth Factor (EGF), as a responsible generator agent of cell differentiation at the mammary epithelial level.

KEY WORDS: Epidermal growth factor; Cellular differentiation; Mammary epithelial.

\section{REFERENCIAS BIBLIOGRAFICAS}

Ball, R. K.; Friis, R. R.; Schoenenberger, C. A.; Doppler, W. $\&$ Groner, B. Prolactin regulation of beta-casein gene expression and of a cytosolic 120-kd protein in a cloned mouse mammary epithelial cell line. EMBO J., 7(7):2089-95, 1988.

Boonstra, J.; Rijken, P.; Humbel, B.; Cremers, F.; Verkleij, A. \& van Bergen en Henegouwen, P. The epidermal growth factor. Cell Biol. Int., 19(5):413-30, 1995.

Brown, G. Method of decreasing cutaneous senescence. Louisville, Bays-Brown Dermatologics, 1997.

Carpenter, G. \& Cohen, S. Epidermal growth factor. Annu. Rev. Biochem., 48:193-216, 1979.

Carpenter, G. \& Cohen, S. Epidermal growth factor. J. Biol. Chem., 265(14):7709-12, 1990.
Cornejo, R.; Joazeiro, P.; Chammas, R.; Montes, G. \& Caldini, E. Morfometría de la diferenciación de células epiteliales mamarias en cultivo. Rev. Chil. Anat., 13(1):33-41, 1995.

Cotran, M.; Kumar, V.; Fausto, N.; Nelso, F.; Robbins, S. \& Abbas, A. Pathologic basis of disease, St. Louis, 2005.

Doppler, W.; Groner, B. \& Ball, R. K. Prolactin and glucocorticoid hormones synergistically induce expression of transfected rat beta-casein gene promoter constructs in a mammary epithelial cell line. Proc. Natl. Acad. Sci. U S A, 86(1):104-8, 1989.

Fallon, J. H.; Seroogy, K. B.; Loughlin, S. E.; Morrison, R. S.; Bradshaw, R. A.; Knaver, D. J. \& Cunningham, D. D. Epidermal growth factor immunoreactive material in the central nervous system: location and development. 
Science, 224(4653):1107-9, 1984.

Gospodarowicz, D. \& Moran, J. S. Growth factors in mammalian cell culture. Annu. Rev. Biochem., 45:53158, 1976.

Groner, B.; Ball, R.; Taverna, D.; Schmitt-Ney, M. \& Hynes, N. Epidermal Growth factor, glucocorticoid hormones and prolactin act sequentially in the induction of milk protein gene expression. In: Sporn, M. Control of growth factor and prevention of cancer. Berlin, Springer Verlag, 1992. pp.27-36.

Guyette, W. A.; Matusik, R. J. \& Rosen, J. M. Prolactinmediated transcriptional and post-transcriptional control of casein gene expression. Cell, 17(4):1013-23, 1979.

Hall, K. The Nobel Prize in Physiology or Medicine 1986. Presentation Speech. The Nobel Foundation, 2009.

Herbst, R. S. Review of epidermal growth factor receptor biology. Int. J. Radiat. Oncol. Biol. Phys., 59(2 Suppl):21-6, 2004.

Hernández-Sotomayor, S. M. \& Carpenter, G. Epidermal growth factor receptor: elements of intracellular communication. J. Membr. Biol., 128(2):81-9, 1992.

Hynes, N.; Taverna, D.; Cella, N. \& Chamas, R. The effect of the extracellular matrix upon HC11 mammary epithelial cell differentiation. Ciencia e Cultura, 44:2536, 1992.

Jimenez de Asua, L. Control mechanisms in animal cells. New York, Reven Press, 1980.

Kumar, M.; Abul, A.; Nelson, F. \& Aster, J. Tissue renewal, Regeneration and repair. Robbins \& Cotran Pathologic Basic of Disease. Philadelphia, Elsevier-Saunders, 2005.

Massagué, J. \& Pandiella, A. Membrane-anchored growth factors. Annu. Rev. Biochem., 62:515-41, 1993.

Taverna, D.; Groner, B. \& Hynes, N. E. Epidermal growth factor receptor, platelet-derived growth factor receptor, and c-erbB-2 receptor activation all promote growth but have distinctive effects upon mouse mammary epithelial cell differentiation. Cell Growth Differ., 2(3):145-54, 1991.

Tonelli, Q. J. \& Sorof, S. Epidermal growth factor requirement for development of cultured mammary gland. Nature, 285(5762):250-2, 1980.
Tsui, L. \& Farral, M. Report of the committee on the genetic constitution of chromosome 7. Human Gene Mapping 11. Cytogenet. Cell Genet., 58:337-81, 1991.

Venturi, S. \& Venturi, M. Iodine in evolution of salivary glands and in oral health. Nutr. Health, 20(2):119-34, 2009.

Dirección para correspondencia:

Prof. Dr. Ricardo Cornejo Uribe

Facultad de Medicina

Universidad de La Frontera

Casilla 54-D, Temuco

CHILE

Email: rcornejo@ufro.cl

Recibido : 03-03-2011

Aceptado:18-06-2011 